Acta Poetica 25-1

PRIMAVERA

2004

\title{
Reflexiones sobre la imitación y la traducción en la academia mexicana del siglo XIx: un texto de José Ramón Pacheco
}

\begin{abstract}
Pablo Mora
Se presenta y se pone en su contexto un ensayo de José Ramón Pacheco (1838) en el que se hace una reflexión, poco frecuente en la prensa mexicana, sobre las diferencias entre la imitación y la traducción, a raíz de una versión al español del poema "El Lago" de Lamartine presentada por [Ignacio] Rodríguez [Galván] en cierta academia mexicana del XIX.

An essay by José Ramón Pacheco (1838) is presented here and set in context. In it, the differences between translation and imitation are explored, taking as a starting point the Spanish version of Lamartine's poem "The Lake", that had been previously made by [Ignacio] Rodríguez [Galván] and read at a literary academy. It was not very often that this topic was addressed in literary newspapers and magazines of the time.
\end{abstract}




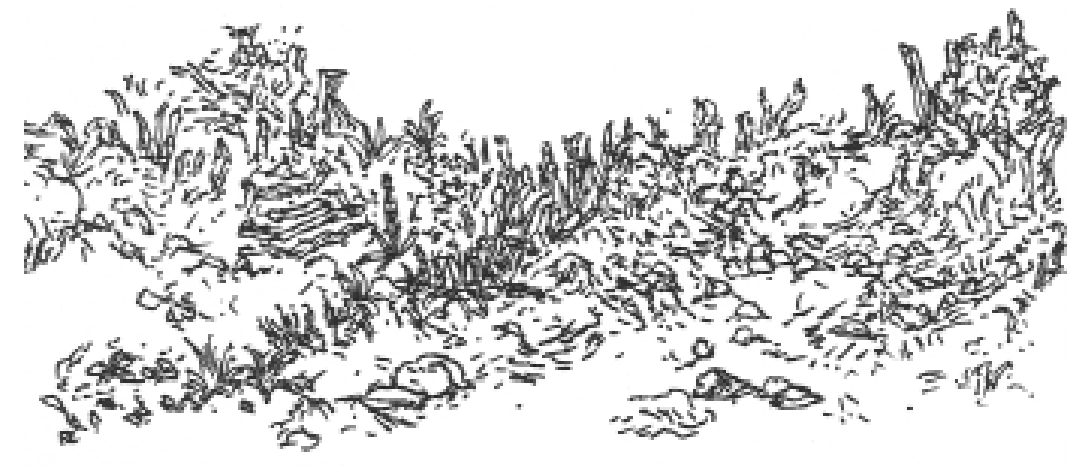


Acta Poetica 25-1

PRIMAVERA

2004

Pablo Mora

\section{Reflexiones sobre la imitación y la traducción en la academia mexicana del siglo XIx: un texto de José Ramón Pacheco}

En la primera parte del siglo XIX la conformación de una literatura nacional fue la pauta que determinó los primeros esfuerzos de los escritores mexicanos. A partir de 1821, la vida nacional se caracterizó por un periodo de caos, revueltas, pronunciamientos, intervención y nula estabilidad política. Dicha situación ha sido la causa más visible que ha utilizado la historiografía literaria para explicar la escasa y pobre producción literaria; sin embargo, como se ha estudiado en la última década, existen en las revistas y en los periódicos una serie de textos significativos preocupados por iniciar una reflexión sobre la nueva función de la literatura, la importancia de ciertas preceptivas, la idea de la traducción y de la imitación, la pertinencia de la prosodia española, etcétera. Particularmente con la conformación de las academias literarias, tales como la Academia de Letrán en 1836-1840 y El Liceo Hidalgo en 1850, así como con el esfuerzo editorial y hemerográfico de la década de los cuarenta, se ha demostrado que hubo intentos claros de sistematizar una reflexión sobre temas como el de la lengua y la literatura. Dichos datos y documentos arrojan luces para entender el proce- 
so de desarrollo de nuestras letras. En el texto que reproducimos a continuación podemos ver una muestra de esa preocupación literaria concreta, derivada de una discusión dentro del ámbito mismo de tertulias y academias; suponemos que, posiblemente, de la Academia de Letrán. ${ }^{1}$ Se trata de un texto aparecido en 1839 en el Diario del Gobierno, ${ }^{2}$ firmado por uno de sus esporádicos colaboradores: José Ramón Pacheco (18051865).

A partir de 1826 uno de los desafíos que inmediatamente se pusieron en evidencia, ante la escasa producción literaria y la “incorrección” prosódica de los textos en español, advertida por la crítica, fue el aprendizaje de la métrica española en aras de un prestigio nacional, según los cánones establecidos del "buen gusto". Al mismo tiempo, la presencia del romanticismo repercutió rápidamente en el interés por difundir otras literaturas extranjeras, de la misma manera en que era reivindicado el valor histórico y de prestigio de la lengua española por parte de autores románticos alemanes (José Ramón Pacheco lo manifiesta en el texto que ahora reproducimos.) El proceso inicial de difusión y crítica lo emprende de manera preponderante el cubano-mexicano José María Heredia en sus revistas, hasta alcanzar un punto más fecundo, años más tarde, en dos revistas clave, producto de las actividades de la Academia de Letrán: El Recreo de las Familias (1838) y los cuatro tomos de El Año Nuevo (1837-1840).

A la luz de este proceso literario, algunos escritores mexicanos muy rápidamente dieron muestras de esa preocupación y de la necesidad de difusión de textos clásicos y modernos: Desde Anastasio de Ochoa con sus traducciones de las $\mathrm{He}$ roidas de Ovidio y de poemas de Nicolás Boileau y Horacio, hasta el cubano-mexicano José María Heredia con traduccio-

\footnotetext{
${ }^{1}$ La otra Academia posible fue la de la Lengua que en aquellos años no registró continuidad en sus trabajos debido al estado de inestabilidad política.

${ }^{2}$ Núm. 1491. México, jueves 30 de mayo de 1839. T XIV.
} 
nes de Byron, Arnault, Osián, Béranger, Campbell y Landívar, entre otros, pasando por autores como Francisco Sánchez de Tagle en poemas como "Pensamientos de los muertos", José Joaquín Pesado con sus traducciones de las "Odas" de Horacio y de poemas de Lamartine, etcétera.

Ahora bien, el proceso de la crítica literaria tiene su origen, a partir del México independiente, en las críticas del español Alberto Lista a la poesía de José María Heredia y, posteriormente, en las críticas de Quintana Roo; pero también, y sobre todo, en juicios que de alguna manera retomará el Conde de la Cortina, quien en 1837 publicó Examen crítico de algunas de las piezas literarias contenidas en el libro intitulado El Año Nuevo, 1837. En dicho folleto Cortina hacía una crítica a algunos de los poemas desprendidos de la actividad de la Academia de Letrán y ponía en evidencia la necesidad del aprendizaje de las reglas prosódicas de la lengua española como requisito indispensable para escribir poesía. Precisamente una de las respuestas y los caminos que adoptaron los miembros de la Academia de Letrán, ante la falta de condiciones políticas y sociales para dedicarse plenamente a la escritura, fue el tradicional ejercicio de la "traducción" como forma de aprendizaje. Es evidente, por ejemplo, la reducción del número de textos originales producidos por los miembros de la Academia de Letrán y, al mismo tiempo, el aumento en el número de las traducciones aparecidas en los dos últimos números de $E l$ Año Nuevo. El texto que presentamos "Sobre la imitación" es también, en buena medida, producto de dicha práctica y discusión.

Este texto de José Ramón Pacheco nos permite entender la forma como los letrados mexicanos privilegiaron una noción de la traducción que tuvo consecuencias y alcances importantes en el desarrollo de nuestras letras. En esos años, dentro de un contexto de reciente intervención extranjera, claramente los escritores buscaban consolidar las bases para la formación de una literatura nacional a partir de la traducción de textos extranjeros en 
formas métricas españolas adecuadas, una adaptación que identificaban con "la imitación". No en vano, ese mismo año aparecieron, en El Recreo de las Familias, textos tan significativos como el poema de Espronceda: "La canción del pirata" y, números después, el poema ejemplar del romántico mexicano Fernando Calderón: "El Soldado de la Libertad". Se trataba, este último, de un texto que buscaba imitar el poema original de Byron pero que, sobre todo, tomaba como modelo el poema del español Espronceda, mostrando una de las consecuencias de la noción que se tenía de la "imitación" frente a la de "traducción". Precisamente el ensayo de José Ramón Pecheco sirve para entender los motivos de dicha producción y las diferencias que se establecían entre "imitar" y "traducir". Así, el texto de Pacheco buscaba muy específicamente responder a una discusión que se había desprendido de la traducción de un texto fundamental del escritor francés más influyente en la lírica mexicana de la primera mitad del siglo XIX: Alfonso de Lamartine. Entonces, nos revela Pacheco en las primeras líneas de su ensayo, se discutía en el interior de la Academia de Letrán si la traducción del poema "El Lago", hecha por Ignacio Rodríguez Galván, era una "imitación" o una "traducción".

Dicha cuestión, por otra parte, daba la oportunidad para revelar a Pacheco algunas de las fuentes bibliográficas que usaban tanto los Letranes como los críticos y las "autoridades". Por ejemplo, Pacheco menciona el texto de Esteban de Arteaga, La belleza ideal (1789), un libro que Menéndez y Pelayo consideraba "el más metódico, completo y científico de los libros de estética pura del siglo XVIII", 3 pero también menciona a un poeta neoclásico como José Manuel Quintana, o bien a una serie de lexicógrafos y escritores representantes de la Ilustración francesa.

Finalmente, habría que decir que José Ramón Pacheco, nacido en Guadalajara en 1805, fue un escritor y discípulo del

${ }^{3}$ Madrid, Espasa-Calpe, 1955, VII. 
padre Juan Cayetano Portugal, maestro éste de José Clemente Munguía. Pacheco fue además cónsul en la República Francesa de 1831 a 1833 y ministro de Justicia en 1846. Viajó a Europa durante 1847 y luego fue Ministro de México en Francia. Fue el representante en México de la frenología y en 1835 publicó Expresión sumaria del sistema Frenológico del Dr. Gall. Publicó además prosa (novela corta) en El Año Nuevo (18371940) y textos varios en El Recreo de las Familias (1838). En 1839 Pacheco publicó una obra editada en libro El Testamento del difunto con el seudónimo de "El Notario de la Familia". Su casa era punto de reunión y asistía también, según cuenta Guillermo Prieto en sus Memorias de mis tiempos, a las tertulias de la casa de Mariano Galván. He aquí el texto de Pacheco:

SOBRE LA IMITACIÓN

[...] Se trata de saber si se puede llamar imitación una obra en que faltan algunas ideas del modelo y en que se ven algunas que aquel no tiene; o de otro modo, si el que imita puede añadir algo suyo a lo que dijo o pensó el autor a quien pretende imitar. Yo dije en la discusión que indudablemente sí, y en el estudio que después he hecho, no he encontrado sino mil razones para confirmarme en esa opinión, sin haber hallado un solo autor ni una sola razón que la contradiga. Así, pues, no puedo hacer ahora otra cosa en desempeño del encargo que tuvo a bien hacerme la academia, que consignar en este escrito, con algún más orden, lo que dije aquella vez improvisando, y recordar a los señores que la componen lo que saben todos mejor que yo que otros dicen.

Pluguiese al cielo que las cuestiones de lo útil se ventilasen con el noble desinterés que las cuestiones de lo bello y que se terminase como en una reunión de amigos de las bellas letras, donde aunque también se tienen afecciones, no son sino las que sugieren la razón y el buen gusto, donde aunque también se destierra la indulgencia y se ejerce la severidad en el juicio, es sólo para abrir el paso al convencimiento del espíritu, a di- 
ferencia de aquellos cuerpos que tienen en sus manos la suerte de muchas generaciones, donde la razón que la llora tiene que ceder el triunfo a la tiranía numérica de jueces incompetentes.

La palabra imitación no significa lo mismo en todas las artes. El mérito de imitar en las artes mecánicas consiste en hacer una obra que no se diferencia en nada de la que ha servido de modelo, aunque sean de distintas materias; y este mérito llega a su último punto de gloria cuando el autor puede decir al que examina las dos obras con empeño de encontrar diferencias, y teniendo una en cada mano, ¿dígame Ud. cuál es el modelo y cuál es la imitación? No es éste el mérito de la imitación en las artes liberales, mucho menos en las bellas letras. Estas son del dominio de la imaginación, y teniendo por primera regla, ante todas, la de agradar, y siendo el buen gusto su juez natural, lejos de estar obligadas a seguir servilmente el giro de su modelo cuando imitan, tienen amplia libertad para dar vuelo a una imaginación feliz, para amenizar un cuadro, para añadir colores más risueños a un jardín ya cultivado con suceso, para hacer más interesante una situación, para tomar un nuevo giro o para, de cualquier modo, tratar mejor un asunto ya tratado ¿Quién podría poner en duda esta verdad?

El genio lleva consigo el sello de tal, aun cuando imita; sobrepasa a su modelo con sus creaciones, con sus más armoniosas ejecuciones, con sus inspiraciones más felices.

¿Qué se proponen los que se ejercitan en las bellas artes y en las bellas letras? ¿No es imitar a la naturaleza? Luego así como en esta imitación primitiva pueden el artista y el poeta preferir la imitación ideal a la servil, y reunir en un cuadro lo que esa naturaleza tiene de bello, esparcido en varios puntos, de la misma manera en la imitación de un autor a otro, puede, el que la hace, usar de toda libertad, sin que su imaginación tenga más límites que los que tiene el universo, y más allá, es decir, que son de su dominio, no sólo el cielo y la tierra, y los infiernos, sino todo lo que puede hacer de real, de posible y de fantástico. Nada más común en todos los siglos, en esta flaca naturaleza humana, tan afecta a la variedad, que una mujer abandonada por su amante. Este asunto ha sido tratado por to- 
dos los pintores, por todos los poetas, por todos los novelistas, imitándose unos a otros, y empeñándose a porfía a quien más interesa al lector o espectador, inventando circunstancias que más concurran a este fin, que produzcan mejor efecto. Y en esta gran contienda ha sido hasta ahora la palma de Ovidio, que nos presenta una amantísima y hermosísima Ariadna, con sus vestidos en desorden, hincada una rodilla en la arenosa playa de una isla desierta, sus cabellos flotando por sus blancos hombros medio desnudos, sus mejillas inundadas en lágrimas, su boca entreabierta y sus pequeñas y mórbidas manos adelantadas hacia donde el viento aleja el bajel del ingrato Teseo.

Todo el mundo ha sentido cuánto sube de punto una emoción trágica con la risa o la alegría inocente, y desde entonces para este mismo asunto se han hecho imitaciones, tratándole de varios modos. Llamaba la atención en la exposición de París de 1833 una escena del cólera puesta en un cuadro. En una casa de donde se acababa de sacar el último cadáver, se veía una pieza retirada y como ignorada: un hermoso niño destinado a perecer de hambre y de abandono, en medio de una populosa ciudad que ignoraba su existencia, despierta al amanecer lleno de contento, con la sonrisa en los labios, y se incorpora en la cuna para llamar con sus manecitas y con sus gracias a la infeliz madre que era el último viviente que quedaba en la casa y que había expirado en la noche. Este asunto di yo a nuestro amigo y compañero el Sr. D. Guillermo Prieto, y lo desempeñó a satisfacción de la academia, como tiene de costumbre. Esta alegría ha sido presentada de una manera que desgarra el corazón, expresada con la música más trágica que se ha imaginado, cuando Norma pierde a su felicidad y a su amante en el momento que acababa de recobrarles, y caminando a la hoguera, consigue que su padre se haga cargo de sus inocentes hijos.

O se desconoce el principio de que todas o las más cosas de cualquier género son susceptibles de mejora, o se debe renunciar al goce de esas mejoras que pueden tener las composiciones literarias, o se debe admitir la novedad imitando para me- 
jorar. ¿Cuántas piezas dramáticas han sido arrinconadas porque sus pensamientos a fuerza de uso han perdido, por decirlo así, el resorte de agradar; o desde su nacimiento murieron, hicieron fiasco, como dicen los italianos, y que fundidas de nuevo y vueltas a refundir, acertaron por fin a complacer a los espectadores y produjeron en manos de los imitadores el efecto que en vano los autores se afanaron por alcanzar? Bastaría por vía de ejemplo citar la historia de Guillermo Tell, referida por La Harpe en su Curso de literatura, ${ }^{4}$ y lo que en el mismo se ve del partido que han sacado todos los autores dramáticos del quid pro quo. Salta, además, en esta cuestión, la observación que en mi concepto no tiene réplica. Al leer o al meditar una obra ajena, se me viene una sola idea, una imagen, una inspiración sobre el mismo asunto que no le ocurrieron al autor, pero que no bastan por sí solas para una composición aparte: ¿la razón de no alterar un modelo al imitar, será una razón suficiente para privar al mundo de aquel pensamiento? Mas entonces, se dirá, mi composición en imitación de tal o tal autor, no es suya, sino mía, será suyo lo que es suyo, y mío lo que es mío, y tal vez el asunto no hará más que ganar en este concurso de autores para tratarle. Puedo yo también desfigurarla de tal modo, imitándole, que se le desconozca enteramente y que no quede más que la invención original, la idea madre.

Si se quiere decir que esas modificaciones accidentales son del dominio de la traducción libre, no se ha dicho nada, porque toda traducción poética no tiene medio entre ser libre o detestable. Y en esto es preciso observar de paso que la gloria no sigue, en la repartición de sus lauros, los principios de la justicia distributiva, ni se adquiere en razón directa del trabajo y del merecimiento. El que tiene un pensamiento nuevo, muchas veces lo tiene ya con su medida, con sus palabras propias y hasta con su rima. Creo que encuentra más pena el que ha de verter de un idioma a otro una composición ajena, por que lo tiene de hacer sin que padezcan los pensamientos, sin que

\footnotetext{
${ }^{4}$ Jean Francois de la Harpe (1739-1803). Destacado crítico francés cuya obra más importante fue muy leída por los mexicanos durante el siglo XIX, uno de los primeros intentos de una historia crítica de la literatura francesa.
} 
los versos pierdan nada de su fluidez, ni de su elegancia, ni de su sonido cadenciado, armónico, numeroso, ni las palabras de su exactitud, no sólo para expresar una emoción, un efecto del alma, sino los grados de esa emoción, sus matices, su caso tal vez condicional, etc., etc., etc....; como que si no hay sinónimos en un idioma propiamente tales, mucho menos los puede haber de un idioma a otro. ¿Hay una palabra en el riquísimo idioma español, el más rico de todos después del alemán, aunque más músico y más sonoro que éste, que corresponda a la ultrajante pilié de los franceses? ¿La "lástima", la "compasión", el "desdén", el "desprecio", son capaces de irritar hasta el punto que aquella palabra, acompañada además de la fanfarrona afectación para pronunciarla? Arriba acabamos de usar la comprensión de fare fiasco, porque no le encontramos equivalente en castellano. Hizo grande sensación en el teatro el drama de George Barnwell, que traduje hace muchos años; pero el público que la aplaudió, no sabía que la privé de varias bellezas del original por la incapacidad en que me hallé de presentárselas como en él se hallaban, con ningún circunloquio, ni de reemplazarle su pérdida con las ideas que yo añadí a la pieza con mi traducción muy libre; sin duda era incapacidad mía y no de mi idioma; mas nadie hasta ahora me ha sacado de los apuros en que yo me vi. Me acuerdo que uno de los cuadros más horrorosamente bellos de aquella composición es la narración que hace al pie del patíbulo el antes virtuoso y después desgraciado joven, de los crímenes a que lo arrastró Millewood, una mujer tan infame como hermosa, que le sedujo el corazón. Cuando refiere que después de hundir el puñal en el pecho de su tío, a quien amaba, corre a recibirle en sus brazos y alcanza a oír su perdón, dice que aún se hallaba la vida "hovering" en sus labios. Aquella acción de las aves cuando se hallan suspensas en los aires, sin remontarse ni abatirse, sin movimiento aparente, pero que se sostienen bamboleándose, o por un sacudimiento rapidísimo y menudísimo de sus alas, es la situación en que se hallaba la vida sobre los labios del moribundo tío de Barnwell, y que se expresa con aquella sola palabra inglesa que ha menester tantas en caste- 
llano. Incontables son las de este idioma que no se pueden traducir a otros. Algunas veces se hallan y aun son muy obvios los equivalentes, pero no pueden entrar en el verso, porque lo resiste el metro, o la rima, o el hemistiquio o la prosodia. A lo pasado, a la eternidad y a la nada, llama Lamartine "sombres abimes"; su traducción fiel y natural es "sombríos abismos"; pero toda la habilidad del Señor Rodíguez ${ }^{5}$ y de la academia no han podido meter estas palabras en su verso, y en esta parte perdió el modelo. ${ }^{6}$

Cuando un traductor ha llegado a expresar los pensamientos de un autor con exacta fidelidad, venciendo todos los obstáculos que hemos pulsado, y manejado su propio idioma, o en el que hace la versión con toda facilidad, la gloria no es para él, sino para el autor original, sin que el lector pulse cuántas más dificultades ha superado el segundo que el primero; porque es condición de todas las grandes obras, que cuanto más perfectas están, es cuando dice el que las ve, que aquello no se podía hacer de otra manera.

Estamos en que la traducción aunque sea libre no es imitación, sino copia, y obligada por lo mismo a reproducir hasta los defectos del modelo. La infidelidad en las versiones de las obras clásicas, hace utilísimo el estudio de los idiomas, aunque no fuese más que por el placer de leer en el suyo y calificar a sus autores, porque dicen los italianos: traduttori, tradittori.

La imitación por el contrario, no debe tomar de aquel sino lo bueno y alejarse cuidadosamente de las incorrecciones o

${ }^{5}$ Se refiere a Ignacio Rodríguez Galván (1816-1842), poeta y dramaturgo mexicano, miembro de la Academia de Letrán y sobrino del impresor Mariano Galván, fue responsable de los anuarios El Año Nuevo (1837-1840) y El Recreo de las Familias (1838) y promotor y protagonista del romanticismo mexicano. Realizó también imitaciones y traducciones de Alejandro Manzini, entre otros.

6 Suponemos que se trata del poema "El Lago" (1817) en la estrofa que comienza: "Éternité, néant, passé, sombres abîmes; / Que faites-vous des tours que vous engloutissez?..." que en traducción de Vicente Bastida (Cátedra 2000) queda como "Eternidad, vacío, pasado, negros abismos, / ¿qué es lo que hacéis de los días que devoráis?..." Rodríguez Galván nunca publicó su traducción de dicho poema, si es que la hubo. Lo que sí publicó fue una imitación de Lamartine que tituló "Un rayo de luna", firmada el 30 de enero de 1838, y que apareció en $E l$ Recreo de las Familias. 
faltas de ideología; dar a su lector a disfrutar el perfume de la rosa sin punzarle con las espinas. La traducción libre sólo puede avanzar a no copiar las incorrecciones gramaticales. En esa misma composición "Al Lago" de Lamartine, ${ }^{7}$ hay una falta gramatical; y esta observación no es de aquellas trabas que el frío gramático se complace por desquite en oponer al vuelo del ingenio, porque basta que el pronombre ella, en la cuarta estrofa, pueda dar lugar a una inteligencia equivocada, o anfibológica, para que se deba observar la regla de la correcta locución.

Según todos estos principios, creo que el carácter que se debe dar a la pieza que dio origen a esta discusión, es el de una traducción y no verdadera imitación. De una o de otra manera, todo ello es primo-hermano del plagio, dicen algunos señores. Yo creo que se equivocan, y que bien se puede imitar a otro con pensamientos todos nuevos, todos bellos, todos originales, aunque no lo sea la clase, el carácter de la composición. Entonces es cuando se compone por el estilo, a semejanza de tal o tal otra composición, que es en mi concepto, el riguroso significado de la imitación. No hace muchos días, la academia y el público han aplaudido una bellísima imitación que no tiene de su modelo ni un solo pensamiento. El Soldado de la libertad, de mi paisano y amigo, D. Fernando Calderón; composición hecha por el estilo del Pirata, de D. José de Espronceda, que a su vez hizo una bella imitación de Lord Byron. ${ }^{8}$

En esta también hay más riesgo, y por consiguiente más mérito, sin haber tanta gloria para el imitador, que para el pri-

${ }^{7}$ Lamartine (1790-1869) fue sin duda uno de los poetas franceses más leídos e influyentes de la primera mitad del siglo XIX mexicano. El libro Primeras meditaciones (1820) contiene poemas tan importantes como "El asilamiento", "La tarde", traducidos por José Joaquín Pesado, o bien, el célebre "El lago" (1817). Las modulaciones políticas, románticas y cristianas de Lamartine en referencia con los movimientos de 1830 y 1848 en Francia fueron seguidas por algunos letrados y políticos mexicanos.

${ }^{8}$ Véase la nota introductoria. Se trata de uno de los poemas más logrados de Fernando Calderón y del romanticismo mexicano. Nos muestra su capacidad de versificación en un texto que sigue a su modelo, trastocándolo, pero siempre fiel a un patrón rítmico y conceptual, de sorprendente maestría. El texto de José de Espronceda apareció en El Artista de Madrid en 1837. 
mer invento, porque se debe tener presente que cuando se oye una imitación, se está pensando en la primera composición que ya se conoce y es necesario no dejar indiferencia en el ánimo, si no se consigue dejar una impresión más agradable y que provoque a ser vuelto a oír y vuelto a ser leído con más placer que a su modelo.

No seamos, pues, rigoristas queriendo desterrar uno de los bellos ejercicios en que se puede emplear el ingenio. Si no todos pueden osar levantarse a la altura de Byron y de Lamartine, déjese a ciertas capacidades algún campo en que poder trabajar y que sea algo más que de meros intérpretes de obras todas ajenas. Ni las leyes económico-políticas de las naciones son exclusivas en sus recompensas para sólo los inventores, y las conceden también a los perfeccionadores y aun a los simples introductores. Los descubridores de la pólvora, de la imprenta y del vapor, son tan raros en el mundo, como los compositores de la Odisea, del Paraíso Perdido, de los Infiernos. Mas ¿cuándo no han aprovechado, por mejor decir, cuándo no han cambiado la condición del género humano, las infinitas mejoras y aplicaciones de aquellos inventos?

Iba a exponer, en cumplimiento de lo ofrecido arriba, las doctrinas de varios autores; pero ya me he extendido demasiado, y bastará remitir a los señores que estuvieron en sentido contrario en la sesión de hoy hace ocho días, a lo que dice Boiste $^{9}$ en su Diccionario de bellas letras, en la palabra imitación: lo que dice Barthez, en su obra Teoría de lo bello, ${ }^{10}$ sexto discurso de las bellezas de la poesía, sección primera de la imitación, etc; D. Esteban de Arteaga, Belleza ideal. ${ }^{11}$ No hay más que decir sino que toda la poesía clásica española del si-

\footnotetext{
${ }^{9}$ Se refiere al lexicógrafo francés Victor Boiste (1765-1824), que escribió el Dictionnaire universel de la langue française (1800).

${ }^{10}$ Pablo José Barthez (1734-1806). Médico y filósofo francés, publicó una obra esencial sobre fisiología en 1778 ("Nuevos elementos de la ciencia del hombre") y el mencionado Traité du beau (1807).

11 Esteban Arteaga (1747-1799). Escritor español que vivió en Bolonia en 1767. Defendió las ediciones sobre Giambattista Bodoni y posteriormente, en 1789, publicó Investigaciones filosóficas sobre la Belleza Ideal considerada como objeto de todas las artes de imitación. Fue también célebre crítico musical.
} 
glo XVI es imitación de la latina y de la italiana: véase el prólogo de Quintana. ${ }^{12}$

Garcilaso en la primera égloga de Salicio y Nemoroso imitó á Virgilio; Fr. Luis de León, en su oda a todos los santos, imitó a Horacio, in laudem deorum; D. Alberto Lista ha hecho muchísimas imitaciones de Horacio, añadiendo y poniendo de su parte pensamientos que Horacio no tuvo, y si se quiere un ejemplo determinado que sirva de examen en esta sesión, tomaremos la oda a Dalmiro en imitación de la de aquel romano, a Tito Séptimo, en donde hallaremos la diferencia de esta imitación a la traducción de la misma oda de D. Javier Burgos. Compararemos también la traducción de este mismo Burgos de la oda a Pósthumo, con la que se ha publicado en el último del Recreo de las familias de D. Joaquín Pesado, ${ }^{13}$ y la academia dará la palma a la que mejor haya usado de su libertad, sin salir de la fidelidad de una traducción.

En fin, si es poca gloria imitar, yo me contentaría con la de Garcilaso, Fr. Luis de León, Herrera, los Lista y los Argensolas.

José Ramón Pacheco

México, Mayo 3 de 1838

12 Manuel José Quintana (1772-1857). Poeta español, modelo del neoclasicismo y poesía cívica en México. Muy concretamente se tomó la poesía "A España, después de la revolución de marzo..." (1808) como ejemplo. Seguramente se refiere a la "Introducción histórica" que escribió para Poesías selectas, desde el tiempo de Juan de Mena hasta nuestros días (1807).

13 Se publicó, en efecto, la "Oda XIV Libro $2^{\circ}$ de Horacio". Lo interesante es que se publica en forma bilingüe, un caso muy raro para entonces (468). 